\title{
Why are online reviews in the sharing economy skewed toward positive ratings? Linking customer perceptions of service quality to leaving a review of an Airbnb stay
}

\author{
Jeroen Meijerink and Emma Schoenmakers
}

\begin{abstract}
Purpose - This study aims to explain why online reviews in Airbnb are skewed toward positive ratings. The authors examine customer perceptions of the service quality of an Airbnb stay as a relevant antecedent of whether customers leave an online review of that Airbnb stay. To this end, the authors test the hypothesis that the relationship between service quality and leaving an online review is linear and positive.

Design/methodology/approach - To test the hypothesis, the authors rely on primary survey data from 177 Airbnb customers combined with secondary data coming from their personal online Airbnb accounts. The authors conducted a binary logistic regression analysis to test the hypothesis.

Findings - The results show that customers' service quality perceptions are positively and linearly related to leaving an online review of an Airbnb stay. In other words, satisfied customers are more likely to leave a review after an Airbnb stay than those who are dissatisfied.

Originality/value - The study is original in two respects. First, it reconsiders the role of customer experiences in explaining online customer reviews. In doing so, it empirically shows that the conventional wisdom of a U-shaped relationship between customer experiences and online reviewing does not hold in the context of the sharing economy. Second, by relying on primary survey data, the authors reveal the risk of dissatisfied customers creating an underreporting bias in online reviews, which ultimately make online reviews of Airbnb skewed toward positive ratings.
\end{abstract}

Keywords Online customer reviews, Sharing economy, Service quality, Word-of-mouth, Airbnb Paper type Research paper

\section{Introduction}

Online reviews by customers are of key importance to the hospitality industry. This especially holds where hospitality services are offered through Airbnb - a "sharing economy" platform that relies on online customer reviews to ensure safe consumer-toconsumer interactions through which strangers share personal, underused goods such as their home (Frenken and Schor, 2017; Oskam and Boswijk, 2016). Online customer reviews help to build trust among strangers that wish to engage in transactions through the sharing economy platform by instilling confidence that peers will not act opportunistically (Ter Huurne et al., 2017). Moreover, online reviews offer several tangible outcomes for those who rent out their personal, underused goods. For instance, research has shown that average online ratings of an Airbnb listing are positively associated with the rate charged for the
Jeroen Meijerink and Emma Schoenmakers are both based at the University of Twente, Enschede, The Netherlands.

Received 27 April 2019 Revised 17 February 2020 Accepted 30 March 2020

(C) Jeroen Meijerink and Emma Schoenmakers. Published in Journal of Tourism Futures. Published by Emerald Publishing Limited. This article is published under the Creative Commons Attribution (CC BY 4.0) license. Anyone may reproduce, distribute, translate and create derivative works of this article (for both commercial and non-commercial purposes), subject to full attribution to the original publication and authors. The full terms of this license may be seen at http://creativecommons.org/ licences/by/4.0/legalcode

This paper forms part of a special section "The future of e-HRM and Artificial Intelligence in the hospitality \& tourism industry", guest edited by Dr Huub Ruel. 
accommodation (Proserpio et al., 2018; Teubner et al., 2017), the income generated through an online platform (Öğüt and Onur Taş, 2012) and the ability to continue renting out accommodations through Airbnb (Teubner and Glaser, 2018).

Given the implications for trust building and financial outcomes, it is of utmost importance that Airbnb users leave online customer reviews. Online reviews from customers who have had bad experiences during an Airbnb stay are particularly important, as this help to weed out unreliable providers and to avoid unjustifiable high rental fees being charged. Although existing research (Litvin et al., 2008; Öğüta and Cezara, 2012) suggests that satisfied and dissatisfied consumers are equally likely to leave online reviews - by presenting a Ushaped relationship between customer experiences and online reviewing - we posit that this does not necessarily hold in a sharing economy context. Specifically, we argue that the sharing economy engenders social exchanges that make satisfied consumers more prone to leave positive reviews. At the same time, dissatisfied customers are less likely to leave reviews due to the non-anonymous nature of reviews that sharing economy platforms require as part of building trust. Available evidence hints at this by showing that distributions of online customer reviews in the sharing economy - and Airbnb in particular are heavily skewed toward positive ratings (Fradkin et al., 2018; Teubner and Glaser, 2018; Zervas et al., 2015). This would imply that the relationship between customer experiences and leaving an online review on Airbnb is more linear than U-shaped. To better understand whether a possible overrepresentation of positive online reviews on sharing economy platforms can be attributed to dissatisfied customers not leaving negative reviews, we set out to test a hypothesis on there being a positive, linear relationship between customers' perceived service quality of an Airbnb stay and them leaving an online review of that stay.

In so doing, we make two contributions to the literature. First, our study shows that current thinking on U-shaped customer experience - online reviewing relationships does not apply to the sharing economy. Instead, by testing for linearity in the service quality - online reviewing relationship, our research highlights the risk of dissatisfied customers creating an underreporting bias in online reviews. Second, in comparison to previous online customer review studies that rely on only secondary data, we also used primary survey data to ensure the inclusion of customers who do and do not leave online reviews (Chen and Law, 2016; Schuckert et al., 2015). This helped to show the relevance of customers' service quality perceptions in explaining why consumers do or do not, leave online reviews.

This paper continues as follows. First, we compare the sharing economy (i.e. Airbnb) to more traditional hospitality contexts (e.g. hotels) to explain our argument for a linear, positive (rather than U-shaped) relationship between customers' service quality perceptions and online customer reviews in the sharing economy. After detailing our methodological approach, we present the results of our survey study. We finalize the paper with a discussion on the conceptual and practical implications of our findings.

\section{Literature review and hypothesis development}

\section{Airbnb versus the traditional hospitality industry}

The term "sharing economy" refers to an economic system where consumers grant each other temporary access to personal, underused goods, often in exchange for a monetary fee (Frenken and Schor, 2017; Hamari et al., 2016). Sharing economy platforms like Airbnb are firms that act as intermediaries and rely on internet-based technologies to establish links between consumers that wish to share a good (Sutherland and Jarrahi, 2018). In the case of Airbnb, the Airbnb platform firm mediates between those who wish to rent out (parts of) their home (i.e. Airbnb hosts) and consumers (e.g. tourists) who are looking for a place to stay. Although operating in the hospitality industry, Airbnb and the individual Airbnb hosts differ from "traditional" hospitality service providers such as hotels on at least three dimensions that may have implications for customers leaving online reviews. 
First, exchange relationships between Airbnb hosts and consumers may be more intimate and personal than those between a hotel and its consumers. According to Frenken and Schor (2017), the act of sharing amounts to consumer-to-consumer, rather than businessto-consumer, exchanges. Instead of renting a room in a hotel, Airbnb users rent a room (or apartment) from a peer (Oskam and Boswijk, 2016). Although hotel guests do interact with individuals (e.g. the hotel staff), interactions are less intimate than in Airbnb stays where the customer enters the private sphere (and life) of the Airbnb host. It should, therefore, not be surprising that customers choose to engage in the sharing economy because of the social benefits it brings (e.g. meeting new people and community belonging) (Hamari et al., 2016; Möhlmann, 2015). This may create a personal bond between an Airbnb host and a customer, which is stronger than the one formed during a transaction between a consumer and a (hotel) firm (Sutherland and Jarrahi, 2018). Consumer-to-consumer interactions in the sharing economy can, therefore, be seen as closer to social exchanges than to mere economic transactions (Proserpio et al., 2018).

Second, Airbnb hosts and the customers who rent their property are strangers to each other (Frenken and Schor, 2017). While, traditionally, sharing took place among acquaintances (e.g. family, friends and neighbors), in the sharing economy, sharing now occurs among individuals who do not know each other. In comparison, hotels may be less alien to their clients, particularly when they are part of a reputable hotel chain that customers can relate to and/or run well-funded marketing campaigns that create brand awareness among customers (Lehdonvirta et al., 2018). As individuals, Airbnb hosts do not have these opportunities. Nevertheless, Airbnb hosts need to signal their trustworthiness to strangers that might wish to rent their accommodation. To be able to do so, and ensure that trusted exchanges among strangers do take place, Airbnb solicits reviews from both Airbnb hosts and their customers (Fradkin et al., 2018; Frenken and Schor, 2017; Oskam and Boswijk, 2016; Sutherland and Jarrahi, 2018; Ter Huurne et al., 2017). These online reviews are not anonymous to foster the creation of the trust (Fradkin et al., 2018). For example, in the case of Airbnb, the online reviews of both Airbnb hosts and their customers are accompanied by the name and photo of the reviewer and a link to the reviewer's personal profile (Ert et al., 2016).

A final distinction is that the evaluation of an Airbnb host's performance is almost exclusively in the hands of customers. Airbnb hosts are not "employed" by the Airbnb platform and are remote from the Airbnb management (Duggan et al., 2019; Meijerink and Keegan, 2019). As such, their operations cannot be supervised by a manager. Airbnb, therefore, in effect almost fully devolves the appraisal of Airbnb hosts to customers through an online review system. This differs from hotels where service providers (i.e. hotel staff) are under the supervision of a line manager who is formally responsible and accountable for evaluating their performance. This responsibility and accountability is in part evidenced by the role of human resource specialists in directing line managers to conduct annual performance interviews and to keep track of staff performance. As Airbnb works with independent actors (i.e. its hosts and consumers), Airbnb cannot make customers responsible for leaving online reviews. Although they are important in building trust, online reviewing by Airbnb customers is entirely voluntary. This is why Airbnb implements a range of policies to nudge customers toward leaving an online review (e.g. communicating the importance of online reviews, providing incentives and mutual rating schemes where hosts and customers only get to see the review of the other when both parties have left a review) (Fradkin et al., 2018). Nevertheless, customers remain free to not leave a review. As discussed below, this arrangement may discourage Airbnb customers who have had a bad experience during an Airbnb stay from leaving a review of the Airbnb listing they rented.

\section{Service quality and its role in explaining leaving online reviews}

The outcome variable of interest in this study is "leaving an online review," which is defined as entering an online review by a customer after staying in an Airbnb listing. As such, we 
are interested in whether customers leave an online review of an Airbnb stay. Note that, we only address online reviewing by customers, online reviewing by Airbnb hosts is outside the scope of this study. Leaving an online review on Airbnb involves two actions by a customer:

1. entering quantified performance indicators by means of online ratings (e.g. five-star schemes); and

2. leaving a written report (Chen and Law, 2016; Fradkin et al., 2018; Racherla et al., 2013).

To seek an explanation of why customers do or do not leave an online review after having stayed in Airbnb accommodation, we study their perceptions of the service quality provided by the Airbnb host. We consider service quality to be a relevant antecedent as it is an important aspect of the customer experience that has been shown to be strongly related to customer behaviors, including online reviewing (De Matos and Rossi, 2008; Jeong and Jang, 2011). In line with others (Akbaba, 2006; Choi and Chu, 2001; Jeong and Jang, 2011), we conceptualize service quality in the context of Airbnb as a multidimensional construct describing the quality of both the Airbnb apartment and the Airbnb host. The identification of these two service quality dimensions also aligns with broader developments in the service quality literature. As noted in the work by Parasuraman et al. (1985) on SERVQAUL, customers' perceptions of service quality are based on their expectations and whether a provided good or service meets these. Besides developing expectations of the Airbnb host (e.g. empathy and reliability), research shows that customer expectations concern so-called tangibles. For instance, in the case of the hospitality industry, customer service quality perceptions generally follow from their perceptions of hotel room quality and staff quality (Akbaba, 2006; Choi and Chu, 2001; Jeong and Jang, 2011). In line with this, we consider the perceived service quality of an Airbnb stay to reflect both the quality of the Airbnb apartment (i.e. quality of the room in terms of cleanliness, comfort and quietness) and the quality of the Airbnb host (i.e. helpfulness, politeness and assurance).

Following expectation-disconfirmation theory (Oliver, 1977), researchers have traditionally pictured a U-shaped relationship between customer experiences (including their perceptions of service quality) and online customer reviews. Here, the idea is that online reviewing occurs when a customer's expectations are greatly exceeded or when a product/ service falls well short of meeting their expectations (Chen and Law, 2016; De Matos and Rossi, 2008; Melián-González et al., 2013). In the case of the former, customers want to tell others about their positive experiences or reciprocate the efforts of the service provider, whereas, in the latter, customers want to vent their negative emotions or warn other potential customers (Hennig-Thurau et al., 2004; Wetzer et al., 2007). On this basis, researchers have proposed that customers who experience very high or very low levels of service quality are more likely to leave online reviews than customers who experience moderate service quality levels (De Matos and Rossi, 2008; Litvin et al., 2008; Öğüta and Cezara, 2012). In support of this claim, research has indeed shown that customer expectation - (dis)confirmation (and particularly perceived service quality) exhibits a U-shaped relationship with online customer reviewing (De Matos and Rossi, 2008; Schuckert et al., 2015).

\section{The arguments for a linear relationship between service quality and online reviewing on Airbnb}

Although relevant, we argue that current expectation - (dis)confirmation thinking on online reviewing does not translate well to the sharing economy context. Rather than following a Ushape, we propose, in the Airbnb context, that the service quality - online customer reviewing relationship is positive and linear. In other words, customers who experience high-level service quality in the sharing economy are more likely to leave online reviews than those who experience low-level service quality. We see three reasons related to the features 
that set Airbnb apart from other hospitality providers that explain why the service quality leaving an online review relationship is positive and linear:

Intimate, personal relationships and leaving an online review on Airbnb. We argue that high quality service results in leaving an online review because of the intimate and personal exchanges that occur in the sharing economy. This is consistent with social exchange theory (Blau, 1964) and the norm of reciprocity (Gouldner, 1960), which predict that individuals reciprocate a favor by engaging in positive behaviors, which benefit the individual from whom the favor originates. In the Airbnb scenario, this could play out by customers who experience good service quality returning the favor to the Airbnb host by leaving a positive online review. In support of this argument, research shows that customers do leave positive online reviews to acknowledge high-level performance by a service provider (Jeong and Jang, 2011). On this basis, we expect that customers who experience high quality service from an Airbnb host are likely to leave an online review after the Airbnb stay.

Stranger sharing and leaving "named" reviews on Airbnb. We posit that the reverse is less likely - that customers who receive poor levels of service quality "reciprocate" by writing a negative online review, in effect as an act of revenge. This would be consistent with research showing that disconfirmation of expectations does not lead customers to take revenge against the provider by negative online reviewing (Wetzer et al., 2007). Although dissatisfied customers may leave reviews to warn others (Hennig-Thurau et al., 2004; Wetzer et al., 2007), we expect that, in the sharing economy, low-level service quality does not motivate customers to leave an online review. We argue that this is due to the nonanonymous nature of the online reviews, which is insisted upon by Airbnb to build trust among strangers that wish to transact through Airbnb (Ert et al., 2016; Fradkin et al., 2018). The requirement to identify oneself in reviews is likely to result in dissatisfied customers being subjected to cognitive dissonance. Here, cognitive dissonance refers to mental discomfort experienced when a person's beliefs clash with new evidence presented to that person (Festinger, 1957). In the sharing economy, the beliefs about a good, and its owner, are shaped by earlier online reviews, with research showing that consumers strongly rely on available reviews to make purchase-related decisions (Ert et al., 2016; Ter Huurne et al., 2017). However, research also shows that these online customer reviews are heavily skewed toward positive ratings (Fradkin et al., 2018; Teubner et al., 2017; Zervas et al., 2015). As such, if consumers opt for Airbnb hosts that have many positive online reviews (Zhao et al., 2015), their expectations are likely to be overly optimistic. This could well lead to cognitive dissonance when the Airbnb stay falls short of the customer's expectations that were developed on the basis of available online reviews. As online reviews in the sharing economy are not anonymized, posting a negative online review alongside the positive reviews of others will likely further increase mental discomfort by giving a feeling to the author that they are somehow different from the majority. On this basis, we would expect customers who experience poor service quality to be less likely to leave an online review as the lack of anonymity in the sharing economy may ultimately act as a constraint.

The voluntary nature of leaving an online review on Airbnb. Leaving a review on Airbnb is voluntary. Consequently, a single minor reason for not leaving a review may cause a customer to refrain. We posit that low service quality experienced during an Airbnb stay may be such a reason because leaving "negative" reviews may be considered to take too much time (Ert et al., 2016; Ter Huurne et al., 2017; Teubner and Glaser, 2018; Zervas et al., 2015). This reasoning is supported by the findings of Racherla et al. (2013), who show that dissatisfied consumers use more words, and thus, spend more time in voicing their concerns in online review schemes. Many dissatisfied customers, we suspect, are not willing to write such lengthy and time-consuming reviews. This would be consistent with the conservation of resources theory (Hobfoll, 2011) that predicts that individuals are motivated to avoid resource loss. Customers who have experienced low-quality service provision have already experienced significant resource losses, as the resources they have already spent 
(particularly money and time investigating available reviews) on renting a good did not lead to positive customer experience. Writing a lengthy negative online review would be a further loss of resources (i.e. time), which, according to the conservation of resource theory, dissatisfied customers will try to avoid. In line with this, we expect that poor service quality will be related to the absence of online reviews in the sharing economy.

Overall, based on the above set of arguments, the socio-technological characteristics of the sharing economy, and Airbnb in particular, are likely to motivate customers who experience good service quality to leave an online review (to reciprocate the efforts of the host), while demotivating those who experience poor service quality (to avoid further increases in cognitive dissonance and additional resource losses). A consequence of this is that online reviews are more likely to be left under conditions of high service quality than poor service quality. On this basis, we propose the following hypothesis:

Hypothesis: There is a positive, linear relationship between customers' perceived service quality of an Airbnb stay and their leaving an online review on the Airbnb platform.

It is important to empirically test this assertion for at least two reasons. First, a situation where customers systematically underreport low-level service quality goes against the attempts by Airbnb to build trust among strangers and ensure that Airbnb hosts do not act opportunistically vis-à-vis customers. As such situations are likely to happen, however, infrequently, future customers could well end up in an Airbnb listing that should have been removed from the platform due to its poor quality if this is underreported by dissatisfied customers. Second, the rate charged by an Airbnb host is positively associated with the Airbnb listing's average online rating (Proserpio et al., 2018; Teubner et al., 2017). This relationship becomes questionable if Airbnb customers who experience low-level service quality systematically underreport their experiences. If this underreporting is systematic, online reputation scores are likely to inflate over time, leading to unjustified increases in rental fees. In effect, customers themselves pay the price for not leaving "negative" reviews.

\section{Methodology}

\section{Study design and participants}

To test our hypothesis, we used online survey data from 177 Airbnb customers and secondary data from the Airbnb online accounts of these customers on their most recent stay in Airbnb accommodation. Given that we are interested in variables that reside on the individual customer-level (i.e. their service quality perceptions and them engaging in the online review process), we decided to focus on a single sharing economy platform to rule out possible effects that the attributes of online platforms might have on online customer reviews. This is relevant as various online platforms incentivize customers to leave online reviews (e.g. offering vouchers or discounts or disclosing mutual reviews if both a customer and host leave reviews) (Fradkin et al., 2018), which need to be controlled for. In addition to controlling for the effects of such incentives by only studying customers from a single platform, we also controlled for such effects by including control variables in our survey to measure customers' perceptions of such incentives offered by Airbnb (see the "control variables" section below).

At the start of the research, there was no list of Airbnb customers available to the research team and so we had to rely on convenience sampling. We took several precautions to mitigate some of the downsides of this sampling approach (most notably the lack of generalizability). First, we recruited participants from around the world. To build our sample, we relied on the help of 10 research assistants from various continents (including Asia, North America, Africa and Europe) who solicited study participants through their local networks. Second, to recruit participants from beyond these personal networks, we also posted invitations on various Airbnb user community groups on Facebook, Linkedln and Reddit. We were concerned that this online recruitment might result in the exclusion of 
Airbnb users who do not write online reviews but our data show that this is unlikely, as 35\% of the participants in our study had not left an online review (see also the "descriptive statistics" section). Finally, to reduce the likelihood that dissatisfied Airbnb customers were underrepresented in our sample because they wanted to avoid further resource loss by taking part in our study, we offered a $€ 50$ Airbnb voucher as compensation for any possible perceived loss of resources (i.e. the time needed to participate in the research).

In line with our variables of interest, the most appropriate unit of analysis for this study is the consumption of a good by a customer because:

- this is what customers develop their service quality perceptions about; and

- this is what customers have to appraise when leaving an online review.

Therefore, the study participants were asked to provide data on their most recent stay in Airbnb accommodation. During May and June 2018, the research participants completed an online survey where they initially reported on the level of perceived service quality of their most recent stay in Airbnb accommodation. They were also asked to report whether they had left an online review after this stay. Second, to substantiate the survey data on customer reviews, we asked the participants to share a screenshot of their online Airbnb account to show whether they had left a review of their most recent stay in an Airbnb accommodation. In total, the respondents had three weeks to complete the online survey and received one reminder. To assure respondents over the confidentiality and anonymity of their responses, we did not use any identifiers and told the respondents that they could strikethrough any of the personal information in the screenshots. This was considered important to avoid dissatisfied customers being unwilling to fill out the survey due to cognitive dissonance and the non-anonymous nature of online reviews. As we used a forced-entry technique, all the returned questionnaires were complete without any missing values.

On average, the research participants were 28 years old (SD $=11$ years), rented their first Airbnb accommodation 2.5 years previously ( $S D=1.5$ years), had rented 3.08 Airbnb properties on average before taking our survey $(S D=2.87)$. Finally, $60 \%$ of the respondents came from Europe, 20\% from North America, 10\% from Asia, 6\% from Africa, 2\% from Australia and $2 \%$ from South America. Of the 177 respondents, $65 \%$ had left an online review of their most recent Airbnb stay while 35\% had not. This split is consistent with insights from secondary data provided by Airbnb, which shows that $67 \%$ of the stays in an Airbnb accommodation result in an online review (Fradkin et al., 2018). On this basis, we concluded that customers who do not leave online reviews on Airbnb are realistically represented in our study.

\section{Measure of service quality}

Customers in the sharing economy evaluate service quality in terms of the quality of the goods and the quality of the provider (Akbaba, 2006; Choi and Chu, 2001; Jeong and Jang, 2011). In the case of Airbnb, the good equates to the accommodation, which is rented by a customer, and the provider is the Airbnb host that owns the accommodation. To measure service quality in the Airbnb context, we used the service quality scale of Choi and Chu (2001). This scale was originally used to measure customers' perceptions of hotel room quality and hotel staff quality. To align with the Airbnb context, we replaced the words "room" and "hotel staff" with "accommodation" and "host," respectively, to measure the quality of the good (four items; e.g. "the accommodation was clean") and the quality of the Airbnb host (seven items; e.g. "the host was polite"). As response options, we used a fivepoint Likert scale ranging from 1 (strongly disagree) to 5 (strongly agree). To test the premise that service quality is a high-order construct formed of the above two service quality subdimensions, we performed a confirmatory factor analysis to see whether our data fitted a measurement model in which customer perceptions of service quality were formed 
by the quality of the good/accommodation and the quality of the host. This model had an acceptable fit $\left(\chi_{(39)}^{2}=70.39 ; \mathrm{NFI}=0.93 ; \mathrm{CFI}=0.97 ; \mathrm{GFI}=0.94 ; \mathrm{RMSEA}=0.07\right.$; and SRMR $=0.06)$ and reliability $(\alpha=0.75)$.

\section{Measurement of online reviewing by customers}

We included a one-item measure in the survey to measure whether the research participants left an online review of their most recent stay in an Airbnb accommodation. The item was formulated as follows: "did you leave an online review on Airbnb after your most recent stay in Airbnb accommodation?" We explained to the respondents how and where they could find the information in their online Airbnb account that indicates whether they left an online review or not. The research participants could respond to the item by answering "no" (0) or "yes" (1). To provide proof of their answer, we asked the respondents to make a screenshot of their personal Airbnb account as evidence to show whether they left an online review. In two instances, the survey response did not match what was presented in the screenshot. In both, the information from the online Airbnb account (i.e. the screenshot) was used in the analysis as this information is more accurate.

\section{Control variables}

To address the possibility of confounding effects, we included several control variables. First, age - which was measured as calendar age - was included because expectations of an Airbnb accommodation may differ with age. Second, we measured the experience of Airbnb by asking when the participants had started using Airbnb (one-item: "in which year did you start using Airbnb?"). Controlling for the number of years that a customer has been renting Airbnb accommodations is important as customers tend to experience higher levels of service quality as their experience with using provided goods and services increases (Meijerink et al., 2016). Third, as more experienced users tend to leave reviews more often (Lee et al., 2011), we also controlled for the effect of the number of past Airbnb stays, which a respondent had made in the previous two years (one-item: "how many times did you yourself book Airbnb accommodation in the past two years?"). Finally, we used three one-item measures to assess customers' motives for leaving online reviews. These three motives relate to curiosity (i.e. "I am always curious to learn how the host evaluated me after I stayed in their accommodation"), duty (i.e. "I feel providing online reviews is a duty I must fulfill") and pressure (i.e. "I feel pressure from Airbnb to provide an online review after a stay in Airbnb accommodation").

\section{Data analysis}

Given the dichotomous nature of our outcome variable (i.e. the customer left an online review or did not), we conducted a binary logistic regression analysis to test our hypothesis. In so doing, we tested three nested regression models. Model 1 included only the control variables. In Model 2, we added the service quality term to test our hypothesis on the positive, linear relationship between perceived customer service quality and online reviewing by a customer. In Model 3, we included a quadratic term of service quality (i.e. service quality squared) to assess whether the relationship between service quality and online reviewing was instead U-shaped. Although this was not our hypothesis, we tested for a U-shaped relationship as studies on online reviewing outside a sharing economy context have proposed such a U-shaped relationship (Melián-González et al., 2013).

\section{Findings}

\section{Descriptive statistics}

The means, standard deviations and correlations for the variables of interest are presented in Table 1. As can be seen, the number of past Airbnb stays significantly and positively 
Table 1 Mean, standard deviation and correlations among the study variables

\begin{tabular}{lcrrrrrrrr} 
Variable & M & SD & 1 & 2 & 3 & 4 & 5 & 6 & 7 \\
\hline 1. Age & 28 & 11.27 & & & & & & & \\
2. Experience & 2.48 & 1.65 & 0.08 & & & & & & \\
3. \# of past Airbnb stays & 3.08 & 2.87 & 0.10 & $0.16^{*}$ & & & & & \\
4. Motive: curiosity & 3.75 & 1.23 & -0.14 & 0.13 & 0.13 & & & & \\
5. Motive: duty & 3.51 & 1.17 & 0.07 & 0.12 & $0.20^{*}$ & $0.41^{* *}$ & & & \\
6. Motive: pressure & 2.91 & 1.18 & -0.01 & 0.05 & 0.11 & $0.26^{* *}$ & $0.32^{* *}$ & & \\
7. Service quality & 3.47 & 0.68 & 0.09 & -0.05 & $0.21^{*}$ & $0.27^{* *}$ & $0.22^{* *}$ & 0.00 & \\
8. Left online review & 0.65 & 0.48 & 0.11 & $0.17^{*}$ & $0.20^{* *}$ & $0.21^{* *}$ & $0.44^{* *}$ & 0.09 & $0.33^{* *}$
\end{tabular}

Notes: ${ }^{* *} p<0.01 ;{ }^{*} p<0.05 ; N=177$ Airbnb customers reporting on their most recent stay in an Airbnb accommodation

correlates with duty, service quality and online reviewing. This means that the more stays that an Airbnb customer has, the more likely they are to feel that leaving online reviews is a duty they should fulfill, to experience higher levels of service quality, and to be more likely to leave an online review. Furthermore, service quality and perceived duty to leave an online review are positively correlated. Finally, leaving an online review is significantly and positively correlated with curiosity, duty and service quality. Not only does this show that customers are more likely to leave a review when they are curious about how their Airbnb host evaluated them and when they feel that leaving online reviews is a duty they ought to fulfill but also provides a first indication that perceived service quality and online reviewing are positively and linearly related. In line with our hypothesis, this means that customers who experience good service quality are more likely to leave an online review than those who experience poor service.

To further check for this hypothesized relationship, we analyzed the secondary data (i.e. the screenshots of the actual Airbnb online reviews) of the respondents that did leave a review by determining the distribution of 1-, 2-, 3-, 4- and 5-star ratings that these customers left online. As can be expected, none of the respondents left a 1-, 2- or 3-star rating, 33\% left a 4 -star rating and $66 \%$ a maximum 5 -star rating. This skewed distribution toward positive reviews offers an indication that satisfied customers are more likely to leave online reviews. We now turn to test the hypothesis to assess whether this can be explained by the level of perceived service quality.

\section{Hypothesis testing: relating perceived service quality with online reviewing}

Our hypothesis suggests that there is a positive, linear relationship between customers' perceived service quality and submitting an online review on a sharing economy platform. Model 2 in Table 2 indicates that perceived service quality is indeed significantly and positively related to leaving an online review $(\beta=0.87 ; p<0.001)$ when controlling for the confounding effect of other variables. This indicates that customers who experience poor service quality are less likely to leave an online review than customers who experience good quality service. On this basis, we can accept our hypothesis.

Further, in Model 2 as shown in Table 2, duty is significantly and positively related to online reviewing $(\beta=0.90 ; p<0.001)$. This indicates that customers are more likely to leave an online review if they feel that leaving online reviews is a duty they should fulfill.

Finally, Model 3 in Table 2 shows that the quadratic term of service quality is not significantly related to online reviewing. This indicates that the relationship between perceived service quality and online reviewing is not U-shaped. 
Table 2 Binary logistic regression results predicting leaving an online review on Airbnb

\begin{tabular}{lccccrr} 
& \multicolumn{2}{c}{ Model 1 } & \multicolumn{2}{c}{ Model2 } & \multicolumn{2}{c}{ Model 3 } \\
Level and variables & $\beta$ & S.E & $\beta$ & S.E & $\beta$ & S.E \\
\hline Intercept & $-13.11^{* * *}$ & 3.47 & $-36.46^{* * *}$ & 9.59 & 114.25 & 215.95 \\
Age & 0.03 & 0.02 & 0.03 & 0.02 & 0.03 & 0.02 \\
Experience & 0.15 & 0.13 & 0.21 & 0.14 & 0.22 & 0.14 \\
\# of past Airbnb usage & 0.07 & 0.08 & 0.02 & 0.08 & 0.02 & 0.08 \\
Motive: curiosity & 0.13 & 0.19 & 0.01 & 0.19 & -0.01 & 0.20 \\
Motive: duty & $0.89^{* * *}$ & 0.21 & $0.90^{* * *}$ & 0.22 & 0.89 & 0.22 \\
Motive: pressure & -0.11 & 0.20 & -0.03 & 0.20 & -0.02 & 0.20 \\
Service quality & & & $0.87^{* * *}$ & 0.32 & -10.22 & 15.89 \\
Service quality & & & & & 0.21 & 0.29 \\
-2 log-likelihood & 150.37 & & 142.82 & & 142.33 & \\
$R^{2}$ & 0.23 & & 0.27 & & 0.27 &
\end{tabular}

Notes: ${ }^{* * *} p<0.001 . N=177$ Airbnb customers reporting on their most recent stay in Airbnb accommodation

\section{Discussion}

In this study, we have sought to explain why customers in the sharing economy do or do not leave online reviews. Online reviewing is considered to be a key element of the sharing economy as it adds a sense of safety to consumer-to-consumer interactions through which strangers share personal, underused goods such as their home or car (Frenken and Schor, 2017; Oskam and Boswijk, 2016). Although existing studies have shown that the relationship between customer experiences and leaving an online review is U-shaped in a more traditional form of exchange, there are reasons to suspect that this does not hold in the context of a sharing economy (e.g. Airbnb). The expectation was that customers who experience poor service provision are less likely to leave online reviews in the context of a sharing economy. The primary goal of this study was, therefore, to test the hypothesis of an alternative, linear and positive relationship between customers' service quality perceptions and leaving an online review in the sharing economy context (specifically, Airbnb). The results supported the hypothesis and have several implications for both research and practice.

\section{Implications for research and practice}

The most significant finding of our study is that the relationship between customer perceptions of service quality and leaving an online review after an Airbnb stay is linear and positive. Previous studies had already shown that the distribution of online customer reviews in the sharing economy is highly skewed toward positive ratings (Fradkin et al., 2018; Teubner et al., 2017; Zervas et al., 2015). These studies, however, could limitedly explain why this is the case as they relied on secondary data provided by online platforms (e.g. Airbnb), which introduced sampling bias by only including customers who leave online reviews and not accessing those who do not. Not only does our survey study confirm the skewness toward positive ratings but also it shows that this is attributable to the fact that customers who experience high-level service quality are more likely to leave an online review than those who experience poor service quality.

The linear, positive relationship that we observed has implications for current thinking on the relationship between customer experiences and online customer reviews. More specifically, it challenges the prevailing logic that the customer experience - leaving an online review relationship is U-shaped, in other words, that customers are more likely to leave a review when their experiences either exceed or fall short of expectations (De Matos and Rossi, 2008; Litvin et al., 2008; Melián-González et al., 2013; Öğüta and Cezara, 2012). Our results confirm that customers whose experiences greatly exceed expectations are indeed likely to 
leave a review, but show that those whose experiences fall short of expectations are less likely to leave a review. In our view, these results can be attributed to the sociotechnological nature of the sharing economy. The consumer-to-consumer interactions in the Airbnb context tend to be personal and intimate (Fradkin et al., 2018; Sutherland and Jarrahi, 2018), which is likely to motivate customers to reciprocate the efforts of a wellperforming Airbnb host by leaving a positive online review (Blau, 1964). On the contrary, customers whose experiences fall short of expectations are less likely to leave a negative online review because of the design of online review systems in the sharing economy. That is, the non-anonymous nature of online reviews (Ert et al., 2016; Fradkin et al., 2018) may disincline dissatisfied customers to leave a negative review because this would create cognitive dissonances (Festinger, 1957). Furthermore, dissatisfied customers may be less likely to leave online reviews because negative reviews inherently take more time to write and imply a loss of resources. Taking together, this means that the willingness of customers to leave online reviews in the sharing economy is likely to be contingent on actions and characteristics of multiple actors including the intermediary platform (through the review scheme it designed), those who rent out an underused good (Airbnb hosts and the level of service quality they provide) and customers (who have posted reviews of past experiences). We believe it would be valuable if future studies examined the characteristics and actions of these actors to uncover the mechanisms through which customer experiences in the sharing economy relate to leaving online reviews.

Our results further show that customers are more likely to leave an online review when they feel that providing online reviews is a duty that they should fulfill. This could, following social exchange processes, further explain the linear, positive relationship between service quality and customer online reviewing. That is, this perceived duty to leave reviews might be seen as an indicator of the norm of reciprocity (Gouldner, 1960), with customers feeling obliged to leave an online review when they are provided with high levels of service quality. In support of this view, our results show that service quality is significantly and positively correlated with the perceived duty to leave online reviews. As such, it is very likely that the propensity of customers to leave online reviews in the sharing economy is strongly driven by social exchange processes. In practice, the sharing economy is characterized by a plethora of social exchanges (Proserpio et al., 2018), all of which may affect the likelihood of customers leaving online reviews. For instance, customers might leave online reviews to reciprocate the efforts of their peers who previously left online reviews and to provide future customers with the information they can rely on to make purchasing decisions (Zhao et al., 2015). Furthermore, customers may also leave online reviews to support the safe and trusted stranger-to-stranger transactions, which online platform firms help to safeguard by installing and maintaining online review and reputation schemes (Ert et al., 2016; Ter Huurne et al., 2017). Accordingly, future studies could investigate the exchange relationships that occur among the different sharing economy actors and how these facilitate social exchanges that motivate customers to leave online reviews.

Our results have an important implication for practice. Namely, the fact that customers are less likely to leave online reviews when they experience poor service quality implies that online Airbnb customer reviews are subject to underreporting bias. Although previous findings on the skewness toward positive reviews already point toward this (Fradkin et al., 2018; Teubner et al., 2017; Zervas et al., 2015), our results show that the experiences of dissatisfied customers are indeed underreported in online customer reviews. This is problematic, as information on important issues such as poor service provision, possible service improvements and underperforming providers is lost. Furthermore, research has shown that the average online rating of an Airbnb listing is positively related to the rental fee charged by the Airbnb host (Teubner et al., 2017). Combined with our results, this implies that Airbnb prices are likely to be inflated and that consumers would pay less if negative reviews were not significantly underrepresented. 
Finally, on a more abstract level, our results suggest that popular arguments on the utility of the "wisdom of the crowd" - that a large group of individuals is more knowledgeable and better equipped to evaluate service provider performance than a small group of experts (Surowiecki, 2004) - are not that valid in this instance. Rather, our results imply that the "wisdom of the satisfied" better describes the nature of the impression gained from online reviews in the sharing economy, as the knowledge on the performance of Airbnb hosts are obtained from a large group of predominantly satisfied users. The "wisdom" obtained from those who are satisfied is unlikely to reflect reality as it is based on the overrepresentation of positive experiences. For online platforms to really tap into the wisdom of the crowd, they need to find ways to motivate dissatisfied customers to leave online reviews. In line with the conservation of resources theory (Hobfoll, 2011), this could be encouraged by compensating for the resources/time, which customers spend on leaving online reviews (discounts, vouchers, etc.). In support of this argument, available evidence suggests that such types of compensation increase the likelihood of customers leaving online reviews (although it is not clear whether these are biased toward negative or positive reviews) (Fradkin et al., 2018). Furthermore, Airbnb could reduce the concerns that dissatisfied customers have with the non-anonymous nature of online reviews by providing the possibility to leave a rating, which is simply aggregated into the overall rating of the host, thereby avoiding the disclosure of the identity of dissatisfied customers. Another option would be for online platforms to offer customers the possibility not to leave a written testimonial.

\section{Limitations and direction for future research}

As with any study, our results should be seen in the light of the limitations of the study. First, we had to rely on a small convenience sample to obtain the primary data that was needed to test our hypothesis. Using a convenience sample could limit the generalizability of our results. Nevertheless, given that the distribution of Airbnb stays, which were and were not evaluated (i.e. $65 \%$ vs $35 \%$ ) by our respondents is almost identical to the distribution found in large-sample studies that relied on secondary data provided by Airbnb (Fradkin et al., 2018) this is not seen as a major concern. Furthermore, the respondents included in our study came from different continents and, although this does not overcome the limitations of small samples, it does imply that our results can be generalized to the broader population of Airbnb customers in as far as their online review behavior is concerned.

Second, our findings results may not be generalizable to platforms other than Airbnb. Although we limited ourselves to customers from a single platform to rule out the effects of platform-level variables, it is important that future studies examine other online platforms in the sharing economy. This would be beneficial because platforms other than Airbnb (e.g. Uber, Hely and Deliveroo) do provide customers with the possibility to leave anonymous reviews or reviews, which take less time to complete (such as Uber's single-item, five-star rating scheme) and, therefore, pose less constraints on leaving negative reviews by dissatisfied customers. Therefore, we would urge future studies to replicate our study among customers of other sharing economy platforms.

Finally, although we have examined the online reviewing habits of customers, we have not studied why Airbnb hosts leave online reviews. This is a limitation, as sharing economy platforms also require the latter group of users to leave online reviews (Fradkin et al., 2018). The motives for Airbnb hosts to leave online reviews may differ from those of customers that stay in their accommodation. For Airbnb hosts, online reviews of customers by previous hosts maybe even more important as they are the ones sharing their valuable goods with strangers. Therefore, future research on the drivers of online customer reviews by those who rent out underused goods could provide useful information. 


\section{Conclusions}

Despite its limitations, we believe that this study has provided important insights into why customers in the sharing economy do or do not leave online reviews. As we had predicted, customers who experience high-level service quality are more likely to leave online reviews than customers who experience poor service quality. Although more research is needed into the mechanisms that explain the positive, linear relationship between service quality and leaving an online customer review, this study explains why the observed skewed distribution of positive online reviews occurs and highlights that available online reviews are likely to be affected by underreporting bias. Further, our study shows that the role of customer experiences in explaining why they leave online reviews needs to be reconsidered.

\section{Acknowledgements}

The authors thank Chynna Wan, Maria Jäger, Chris Sleurink, Benni Schubert, Christian Classen, Janik Gerlach, Nour Tawfik, Leon Wächtler, Sarah Petermann, and Nhu Phan for their assistance with the data collection. Furthermore, the authors thank Dr Huub Ruel, the anonymous reviewer, the participants of the "Platform Economy Workshop" (Utrecht, The Netherlands, February 6, 2019), participants of the "First International Hospitality Management Symposium" (Amsterdam, The Netherlands, March 28-29, 2019) and the participants of the "Reshaping Work Conference" (Amsterdam, The Netherlands, October 24-25, 2019) for their helpful comments.

\section{References}

Akbaba, A. (2006), "Measuring service quality in the hotel industry: a study in a business hotel in Turkey", International Journal of Hospitality Management, Vol. 25 No. 2, pp. 170-192.

Blau, P.M. (1964), Exchange and Power in Social Life, New York, NY: Wiley.

Chen, Y.-F. and Law, R. (2016), "A review of research on electronic word-of-mouth in hospitality and tourism management", International Journal of Hospitality \& Tourism Administration, Vol. 17 No. 4, pp. 347-372.

Choi, T.Y. and Chu, R. (2001), "Determinants of hotel guests' satisfaction and repeat patronage in the Hong Kong hotel industry”, International Journal of Hospitality Management, Vol. 20 No. 3, pp. 277-297.

De Matos, C.A. and Rossi, C.A.V. (2008), "Word-of-mouth communications in marketing: a meta-analytic review of the antecedents and moderators", Journal of the Academy of Marketing Science, Vol. 36 No. 4, pp. 578-596.

Duggan, J., Sherman, U., Carbery, R. and McDonnell, A. (2019), "Algorithmic management \& app-work in the gig economy: a research agenda for employment relations \& HRM", Human Resource Management Journal.

Ert, E., Fleischer, A. and Magen, N. (2016), "Trust and reputation in the sharing economy: the role of personal photos in Airbnb”, Tourism Management, Vol. 55, pp. 62-73.

Festinger, L. (1957), A Theory of Cognitive Dissonance, Evanston: Rew, Peterson.

Fradkin, A. Grewal, E. and Holtz, D. (2018), "The determinants of online review informativeness: evidence from field experiments on Airbnb", Retrieved from.

Frenken, K. and Schor, J. (2017), "Putting the sharing economy into perspective", Environmental Innovation and Societal Transitions, Vol. 23, pp. 3-10.

Gouldner, A.W. (1960), "The norm of reciprocity: a preliminary statement", American Sociological Review, Vol. 25 No. 2, pp. 161-178.

Hamari, J., Sjöklint, M. and Ukkonen, A. (2016), "The sharing economy: why people participate in collaborative consumption", Journal of the Association for Information Science and Technology, Vol. 67 No. 9, pp. 2047-2059

Hennig-Thurau, T., Gwinner, K.P., Walsh, G. and Gremler, D.D. (2004), "Electronic word-of-mouth via consumer-opinion platforms: what motivates consumers to articulate themselves on the internet?", Journal of Interactive Marketing, Vol. 18 No. 1, pp. 38-52. 
Hobfoll, S.E. (2011), "Conservation of resource caravans and engaged settings", Journal of Occupational and Organizational Psychology, Vol. 84 No. 1, pp. 116-122.

Jeong, E. and Jang, S.S. (2011), "Restaurant experiences triggering positive electronic word-ofmouth (eWOM) motivations", International Journal of Hospitality Management, Vol. 30 No. 2, pp. 356-366.

Lee, H.A., Law, R. and Murphy, J. (2011), "Helpful reviewers in TripAdvisor, an online travel community", Journal of Travel \& Tourism Marketing, Vol. 28 No. 7, pp. 675-688.

Lehdonvirta, V., Kässi, O., Hjorth, I., Barnard, H. and Graham, M. (2018), "The global platform economy: a new offshoring institution enabling emerging-economy microproviders", Journal of Management.

Litvin, S.W., Goldsmith, R.E. and Pan, B. (2008), "Electronic word-of-mouth in hospitality and tourism management", Tourism Management, Vol. 29 No. 3, pp. 458-468.

Meijerink, J.G. and Keegan, A. (2019), "Conceptualizing human resource management in the gig economy: toward a platform ecosystem perspective", Journal of Managerial Psychology, Vol. 34 No. 4, pp. 214-232.

Meijerink, J.G., Bondarouk, T. and Lepak, D.P. (2016), "Employees as active consumers of HRM: linking employees' HRM competences with their perceptions of HRM service value", Human Resource Management, Vol. 55 No. 2, pp. 219-240.

Melián-González, S., Bulchand-Gidumal, J. and González López-Valcárcel, B. (2013), "Online customer reviews of hotels: as participation increases, better evaluation is obtained", Cornell Hospitality Quarterly, Vol. 54 No. 3, pp. 274-283.

MöhImann, M. (2015), "Collaborative consumption: determinants of satisfaction and the likelihood of using a sharing economy option again", Journal of Consumer Behaviour, Vol. 14 No. 3, pp. 193-207.

Ögüt, H. and Onur Taş, B.K. (2012), "The influence of internet customer reviews on the online sales and prices in hotel industry", The Service Industries Journal, Vol. 32 No. 2, pp. 197-214.

Ögüta, H. and Cezara, A. (2012), "The factors affecting writing reviews in hotel websites", Procedia Social and Behavioral Sciences, Vol. 58, pp. 980-986.

Oliver, R.L. (1977), "Effect of expectation and disconfirmation on postexposure product evaluations: an alternative interpretation", Journal of Applied Psychology, Vol. 62 No. 4, pp. 480.

Oskam, J. and Boswijk, A. (2016), "Airbnb: the future of networked hospitality businesses", Journal of Tourism Futures, Vol. 2 No. 1, pp. 22-42.

Parasuraman, A., Zeithaml, V.A. and Berry, L.L. (1985), "A conceptual model of service quality and its implications for future research", Journal of Marketing, Vol. 49 No. 4, pp. 35-48.

Proserpio, D., Xu, W. and Zervas, G. (2018), "You get what you give: theory and evidence of reciprocity in the sharing economy", Quantitative Marketing and Economics, Vol. 16 No. 4, pp. 371-407.

Racherla, P., Connolly, D.J. and Christodoulidou, N. (2013), "What determines consumers' ratings of service providers? An exploratory study of online traveler reviews", Journal of Hospitality Marketing \& Management, Vol. 22 No. 2, pp. 135-161.

Schuckert, M., Liu, X. and Law, R. (2015), "Hospitality and tourism online reviews: recent trends and future directions", Journal of Travel \& Tourism Marketing, Vol. 32 No. 5, pp. 608-621.

Surowiecki, J. (2004), "The wisdom of the crowds: Why the many are smarter than the few and how collective wisdom shapes business", Economies, Societies and Nations, New York, NY: Doubleday.

Sutherland, W. and Jarrahi, M.H. (2018), "The sharing economy and digital platforms: a review and research agenda", International Journal of Information Management, Vol. 43, pp. 328-341.

Ter Huurne, M., Ronteltap, A., Corten, R. and Buskens, V. (2017), "Antecedents of trust in the sharing economy: a systematic review", Journal of Consumer Behaviour, Vol. 16 No. 6, pp. 485-498.

Teubner, T. and Glaser, F. (2018), Up or out -The Dynamics of Star Rating Scores on Airbnb. Paper Presented at the Twenty-Sixth European Conference on Information Systems, Portsmouth.

Teubner, T., Hawlitschek, F. and Dann, D. (2017), "Price determinants on Airbnb: how reputation pays off in the sharing economy", Journal of Self-Governance \& Management Economics, Vol. 5 No. 4, pp. 53-80. 
Wetzer, I.M., Zeelenberg, M. and Pieters, R. (2007), "Never eat in that restaurant, I did!': exploring why people engage in negative word-of-mouth communication", Psychology and Marketing, Vol. 24 No. 8, pp. 661-680

Zervas, G. Proserpio, D. and Byers, J. (2015), "A first look at online reputation on Airbnb, where every stay is above average".

Zhao, X., Wang, L., Guo, X. and Law, R. (2015), "The influence of online reviews to online hotel booking intentions", International Journal of Contemporary Hospitality Management, Vol. 27 No. 6, pp. 1343-1364.

\section{Corresponding author}

Jeroen Meijerink can be contacted at: j.g.meijerink@utwente.nl

For instructions on how to order reprints of this article, please visit our website: www.emeraldgrouppublishing.com/licensing/reprints.htm

Or contact us for further details: permissions@emeraldinsight.com 